\section{Educating the data user: online information retrieval}

by Ida Lowe ${ }^{1}$

Baruch College, City University of New York

${ }^{1}$ Presented at the International Association for Social Science Information Service and Technology (1ASSIST) Conference held in Washington, D.C., May 26-29, 1988
In a rapidly changing environment in which current accurate information is a key element in staying up-to-date and maintaining an edge in an ever-more-competitive marketplace, access to on-line databases and information services is definitely worthwhile.

Baruch College Library has been offering access to online information since 1981. Currenty, we subscribe to about twelve online services, which provide access to bibliographic, textual, and numeric databases. In the beginning the service was available only through intermediaries (i.e. trained expert searchers), but as demand has increased, direct access by end users (i.e. those who actually need the information, but who are, in general, inexperienced searchers), has been provided.

\section{Obstacles to Accessing Online Databases}

The major obstacle to accessing online databases is that information online is costly. In general, online services charge for every second of time that one is connected, and retrieving information can be a very expensive endeavor, even when the search is performed by an expert and more so when performed by an end user. Some services offer special academic rates. For example, Dow Jones News/Retrieval charges academic institutions a monthly flat fee for unlimited access to most of their databases. This service offers comprehensive company and industry information, as well as general business information. In addition, major services such as Dialog, BRS, and Orbit offer special training as well as 'after hours' agreements which provide access to most of their databases at greatly discounted rates. Baruch College Library has taken advantage of all these special rates in order to make online access available to end users. 
The second major obstacle is that getting the information is not easy. The nature of the majority of databases makes it difficult to extract information from them. Most online databases were originally created to be accessed directly not by the end user of the information, but by intermediaries working on his or her behalf. Those intermediaries were information professionals, usually librarians, familiar with the particular jargon and structure that apply to information-searching in the library field. As a result, the interface to most online databases was structured for their needs.

Not surprisingly, a lot more work and a great deal of confusion occurs when end users try to get at such information on their own. For most online databases, the situation comes down to the end user needing to learn the information professional's language and methods if he or she wants direct access to information. Users who want or need to conduct their own searches for information have to invest some time and effort in learning how to use these systems. In the process, they often have to deal with almost as many information retrieval formats as there are databases. Most online services strongly recommend training for new users. For example, Dialog already has a two-day training session for beginners, and half- to full-day sessions for special categories of databases, such as business and economics. However, for the end user who will need to use the system only once in a while, this training may be too much, and will generally be wasted for lack of practice.

There is a movement among online services to make at least some of their information more accessible to users who are not information professionals. Dialog Information already has two services that provide simplified access: the Business Connection allows users to easily access detailed information on thousands of corporations and businesses, and the Medical Connection provides menu-driven access to information on clinical medicine and medical research.

EasyNet, a service of Telebase Systems Inc. of Narberth, Pa., attempts to overcome the potential confusion inherent in trying to interface with so many different databases by providing a single user interface that quizzes the user in order to narrow down and define the information he or she is seeking. EasyNet then uses that information to determine which databases it should access and how to conduct the search. EasyNet serves as a central access point to approximately 900 database and information services. There are hidden disadvantages of which users may not be aware, including restrictions on the number of databases or type of information that can be accessed.

Also, recent developments of more sophisticated, user friendly interfaces are making end user searching easier. Prosearch, from Personal Bibliographic Software, allows the user to access any database on Dialog or BRS without specific knowledge about the databases or the systems. By using a scheme of menus and submenus, the information seeker can set up a search statement and verify its correctness before logging on to the system. Prosearch provides descriptions of each database structure. All the user has to do is highlight the database fields and type the necessary keywords. Prosearch uses this information to construct the search statement.

Users who want access to on-line information must take the time to learn the best way to get at the information, or at least make sure they have access to someone who can.

A final problem users may face is that, even if they are able to easily access the type of information they need, it may not be in a form that is especially useful to them. The more useful services make information available in a form that can easily be incorporated into dBASE III, Lotus 1-2-3 or similar formats. 
The development of databases on CD-ROM will contribute substantially to the solution of all three problems enumerated above, i.e. there are no connect charges, the access software can be simple and effective, and the user can have a choice of formats of the information retrieved. One database producer that has successfully taken advantage of this medium is Disclosure, a database containing financial information on public companies. The end user can search Disclosure effectively without any knowledge of Boolean logic, truncation, field delimiters, etc., and download the information into Lotus 1-2-3, or ASCII for use with SPSSx or SAS.

Taking all these obstacles into consideration, a plan to promote the use of information online was developed at Baruch College.

The first factor to be considered was the audience we wanted to reach:

- Undergraduate students, the majority of whom are business majors,

* Graduate students, business and education majors (we subdivide this group further into masters degree candidates, doctoral students,and research assistants), and

- Faculty. At present online information retrieval services are completely subsidized by the College. Searches done by professional librarians (intermediaries) are not available to undergraduates.

In order to serve our patrons, we developed several approaches:

\section{At the undergraduate level, online} information retrieval is introduced in the basic library course, which is a three-credit course, part of the core curriculum for all students at the College. A more advance course on online information retrieval is offered for juniors and seniors. The students are introduced to basic concepts such as Boolean logic, truncation, proximity operators, field delimiters, and basic search strategy preparation. The systems introduced are Dow Jones News/Retrieval, a menu-driven system, and Dialog, a command-driven system. The goal of the course is to provide the student with enough of the basic concepts, so as to enable him or her to learn a new system without too much trouble. They learn that the basic concepts apply to all systems, only the mechanics change. A similar course is offered at the graduate level in the Masters in Educational Technology program. The command-driven system introduced in the latter course is BRS, because this is the prevalent system in elementary and secondary schools.

2. Online information retrieval workshops are offered to graduate students and faculty. These workshops last four hours, and the participants learn to search Dialog and BRS using Prosearch. Anyone who has taken this workshop is then allowed to do their own searching in a special information lab. The lab has five IBM XT's with 1200 baud modems. Each computer has Prosearch set up with the appropriate passwords, and keeps track of all searches. A trained research assistant supervises the $\mathrm{lab}$ and provides basic assistance. If the searcher needs more help, a professional librarian can be consulted.

3. In addition to the general application workshop described above, special subject-oriented workshops are offered to thesis students and research assistants. For example, accounting and finance students can take a workshop on accessing 1. P. Sharp (a service which contains over 40 million time series of primarily economic and financial data), learn to download time series data to a diskette, and upload them to the City University of New York central computer for use with such statistical 
packages as SAS or SPSS.x.

4. Doctoral students are required to take a research methods course in which they are taught to use Prosearch for online information retrieval, and are expected to use it throughout the semester for all their projects.

5. In order to promote the use of those systems which are simple to use, and require no special training, such as Dow Jones News/Retrieval and databases on CD-ROM, we hold biweekly demonstrations for anyone interested. The emphasis in the workshops and demonstrations is on 'hands on' experience. We make sure ALL participants carry out a search.

6. Finally, we distribute to all faculty promotional literature on new products that we acquire or to which we subscribe.

Baruch College has been offering these programs for several years. The form and content have changed to keep up with new developments, but the purpose remains the same, i.e. to make every member of the Baruch College community "online information literate." I feel quite confident that we have been successful. $\square$ 